\title{
Ameloblastic carcinoma of the mandible: A case report
}

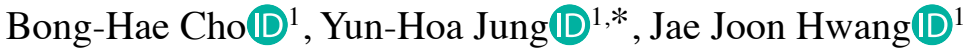 \\ ${ }^{1}$ Department of Oral and Maxillofacial Radiology, School of Dentistry, Pusan National University, Yangsan, Korea
}

\section{ABSTRACT}

\begin{abstract}
Ameloblastic carcinoma is a rare odontogenic malignant tumor with the histologic features of both ameloblastoma and carcinoma. It occurs more frequently in the mandible than in the maxilla and it may appear de novo or develop from a preexisting ameloblastoma or odontogenic cyst. Rapidly progressing, painful swelling is the most common symptom, and radiographically, it shows significant bone resorption and cortical perforation. This report described a case of ameloblastic carcinoma in a 45-year-old man who presented with swelling in the left mandible. The lesion showed combined features of benign findings, such as an expansile cortex with a distinct border, and malignant findings, such as a large exophytic mass with frank bone resorption. Excisional biopsy was performed and a final diagnosis of ameloblastic carcinoma was made.(Imaging Sci Dent 2020; 50: 359-63)
\end{abstract}

KEY WORDS: Ameloblastoma; Mandibular Neoplasms; Radiography, Panoramic

According to the World Health Organization's classification in 2017, odontogenic carcinomas include ameloblastic carcinoma, primary intraosseous carcinoma, sclerosing odontogenic carcinoma, clear cell odontogenic carcinoma, and ghost cell odontogenic carcinoma. ${ }^{1}$ Malignant variants of ameloblastoma include metastasizing ameloblastoma, which appears benign microscopically yet metastasizes, and ameloblastic carcinoma, which exhibits the histopathologic features of both ameloblastoma and carcinoma. ${ }^{2}$

Ameloblastic carcinoma is an extremely rare, aggressive, malignant epithelial odontogenic tumor. It shows a distinct predilection for the mandible, as two-thirds of these tumors arise in the mandible and one-third originate in the maxilla. ${ }^{3}$ It may arise de novo or originate from a preexisting ameloblastoma or odontogenic cyst. ${ }^{4-6}$ Ameloblastic carcinoma has been reported to affect a wide range of age groups and there is no proven sex predilection, although some studies have described a male predominance. ${ }^{7,8} \mathrm{Clin}-$ ically, the most common complaint is swelling, although others include associated pain, ulceration, trismus, and par-

This study was supported by a 2-year research grant from Pusan National University. Received July 21, 2020; Revised September 3, 2020; Accepted September 8, 2020 *Correspondence to : Prof. Yun-Hoa Jung

Department of Oral and Maxillofacial Radiology, Pusan National University Denta Hospital, Geumoro 20, Mulgeum-eup, Yangsan-si, Gyeongsangnam-do 50612, Korea Tel) 82-55-360-5255,E-mail) yhjung@ pusan.ac.kr aesthesia. $^{7,9}$

The reported radiographic manifestations of ameloblastic carcinoma vary. It might present as a cystic lesion with benign features or as a large-tissue mass with significant bone resorption. ${ }^{8}$ Ameloblastic carcinoma tends to be aggressive and shows local bone destruction, occasionally with focal radiopacities, which are extremely unusual for ameloblastoma. ${ }^{7,10}$ Metastasis to regional lymph nodes or the lungs has been reported. ${ }^{7,11}$ As such, diagnostic imaging for treatment planning is very important. ${ }^{2}$ There are some dissenting opinions regarding the treatment of ameloblastic carcinoma, but wide surgical excision is the most commonly used treatment modality. ${ }^{4}$

Because of the rarity of ameloblastic carcinoma, little is known about its clinical and radiographic features, biological behavior, treatment, and prognosis. The purpose of this report was to present a case of ameloblastic carcinoma of the mandible with a description of its clinical and histopathologic features.

\section{Case Report}

This study was approved as "exempt" by the Institutional Review Board of Pusan National University Dental Hospital in Yangsan, Korea. 
A 45-year-old male patient presented with a tumorous mass involving the left posterior mandible. He first felt dull pain at the site and he had left mandibular posterior teeth extracted 6 years ago at a dental clinic. He stated that he had noticed a soft-tissue mass that had been growing slowly for 5 years. Besides swelling, he did not complain of any other symptoms including paresthesia. He was a heavy smoker, smoking 30 cigarettes a day. Otherwise, the review of systems showed no significant findings. Extraorally, he showed facial asymmetry due to left mandibular swelling. The skin over the swelling was smooth and normal. Oral examination revealed a cauliflower-like exophytic mass measuring $7 \mathrm{~cm} \times 5 \mathrm{~cm}$ and extending from the left mandibular canine to the left retromolar pad area. The overlying mucosa was reddish-pink in color and soft to firm in consistency (Fig. 1).

Panoramic radiography revealed severe bone resorption involving the body and ramus of the left mandible with a

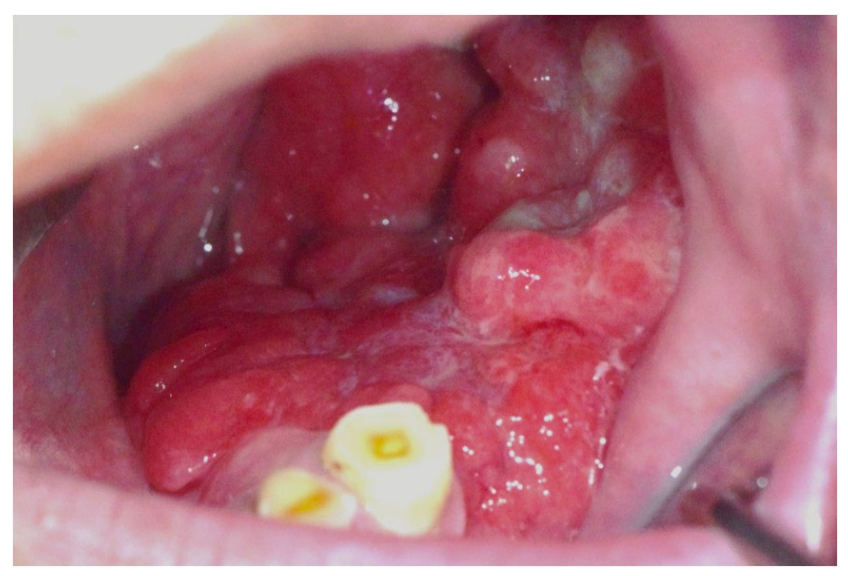

Fig. 1. Intraoral examination reveals a cauliflower-like exophytic mass with a smooth surface in the left mandibular posterior region. soft-tissue mass shadow. The left first and second premolars and the left first and second molars were missing, and the left third molar was floating. The remaining bone surrounding the lesion was sclerotic (Fig. 2). Cone-beam computed tomography (CT) showed a radiolucent radiographic manifestation of frank bone destruction with residual bone remnants and multilocular, expansile cortical resorption (Fig. 3). CT scans showed an enhancing mass with necrotic foci, extending into the surrounding soft tissue. The underlying mandible was severely resorbed and several lymph nodes were enlarged (Fig. 4). These clinical and radiographic findings implied that this lesion had both a benign and malignant nature. However, the extensive infiltration of the necrotic mass into the adjacent soft tissue and aggressive bone resorption signified malignancy. The differential diagnosis included malignant ameloblastoma, ameloblastic carcinoma, or a primary intraosseous carcinoma ex-odontogenic cyst. Additional chest X-rays revealed no abnormal signs, including metastasis to the lungs. Wide excision and segmental mandibulectomy with fibula-free-flap reconstruction were performed.

Histologically, the tumor nest was composed of a core of stellate reticulum-like cells and peripheral columnar cells showing distinct ameloblastomatous features; however, malignant features such as hypercellularity, cellular pleomorphism, and abnormal mitosis were observed at high magnification (Fig. 5). The cervical and submandibular lymph nodes were tumor-free, and a diagnosis of ameloblastic carcinoma was made. The patient was followed up for a period of 3 years with neither recurrence nor metastasis.

\section{Discussion}

There has been controversy over the classification and

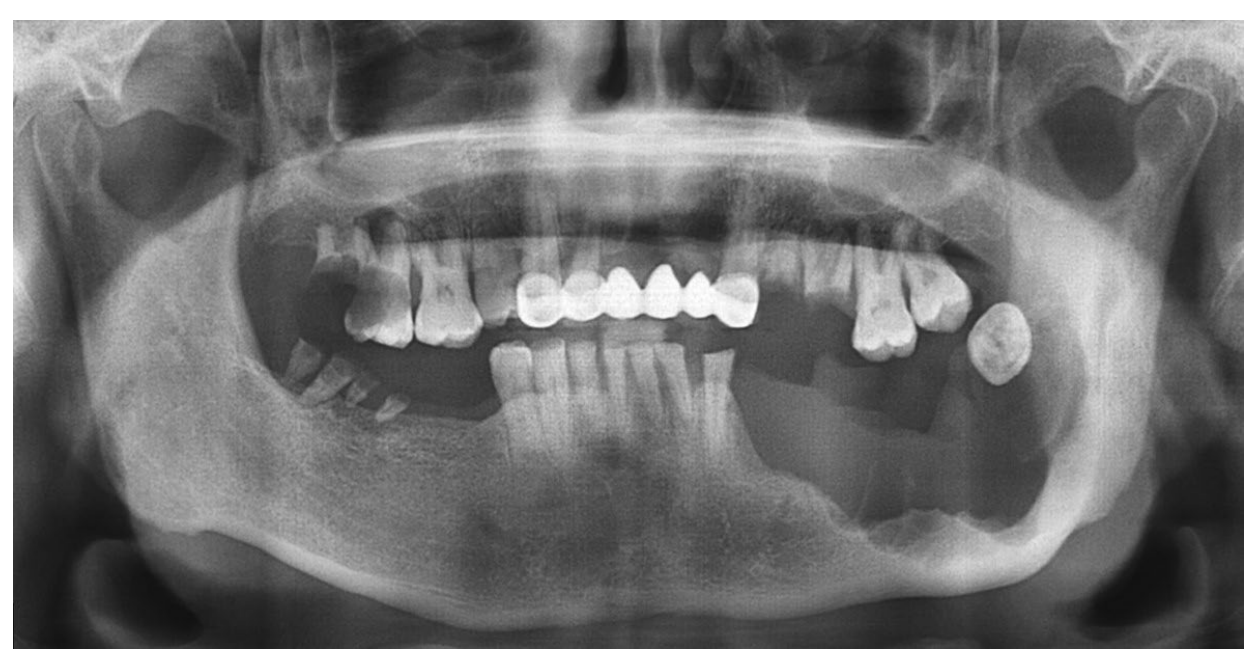

Fig. 2. Panoramic radiograph shows extensive bone resorption with a soft tissue mass shadow. The remaining left mandibular third molar was floating. The border, other than the less distinctive upper side, was well-demarcated and sclerotic. 

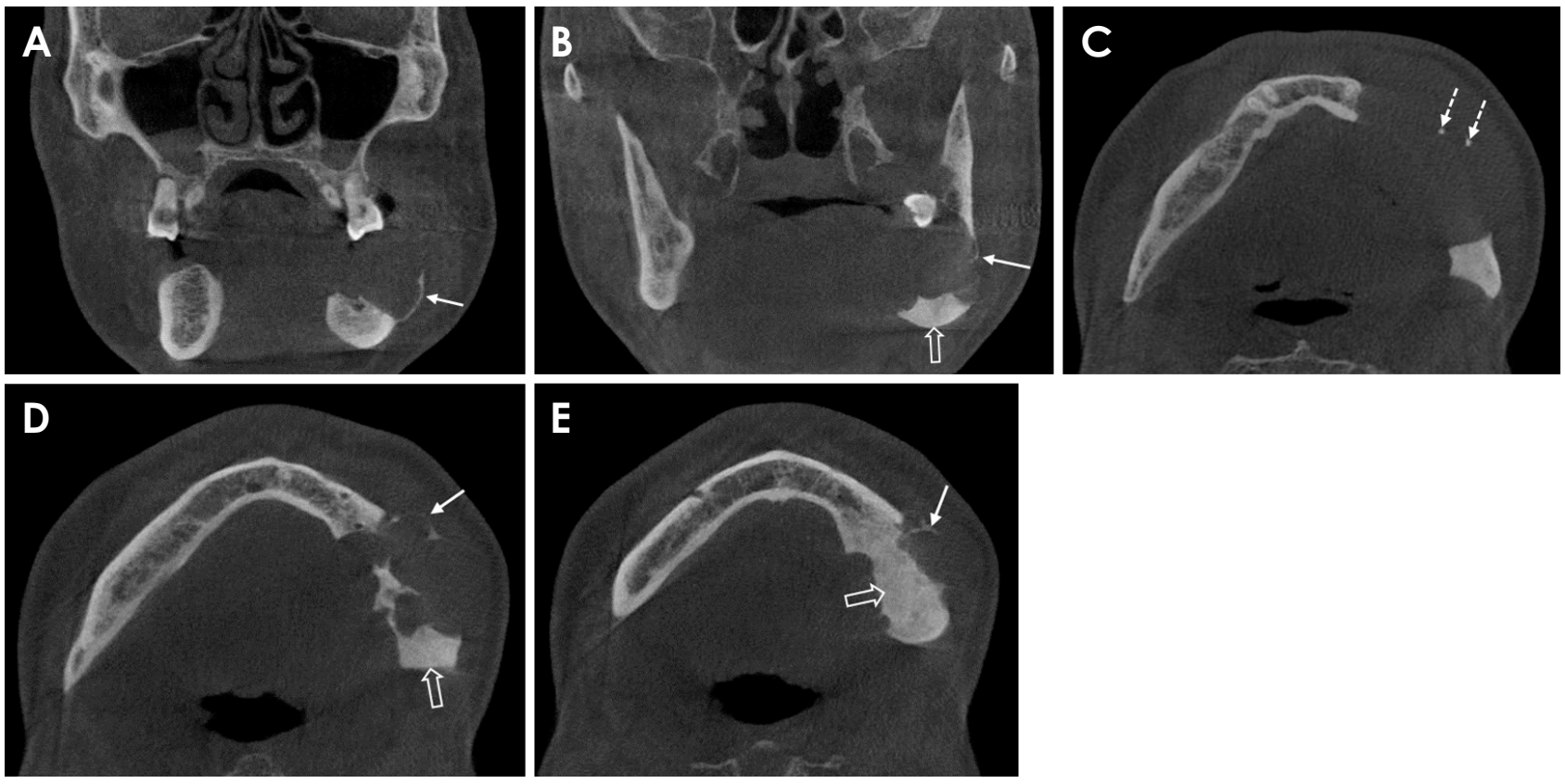

Fig. 3. Coronal (A and B) and axial (C-E) cone-beam computed tomographic images show either multilocular cortical expansion (arrows) or frank cortical resorption with marginal sclerosis (open arrows). The small bone particles (dotted arrows) observed in $\mathrm{C}$ are not calcification, but cortical remains remaining from resorption.
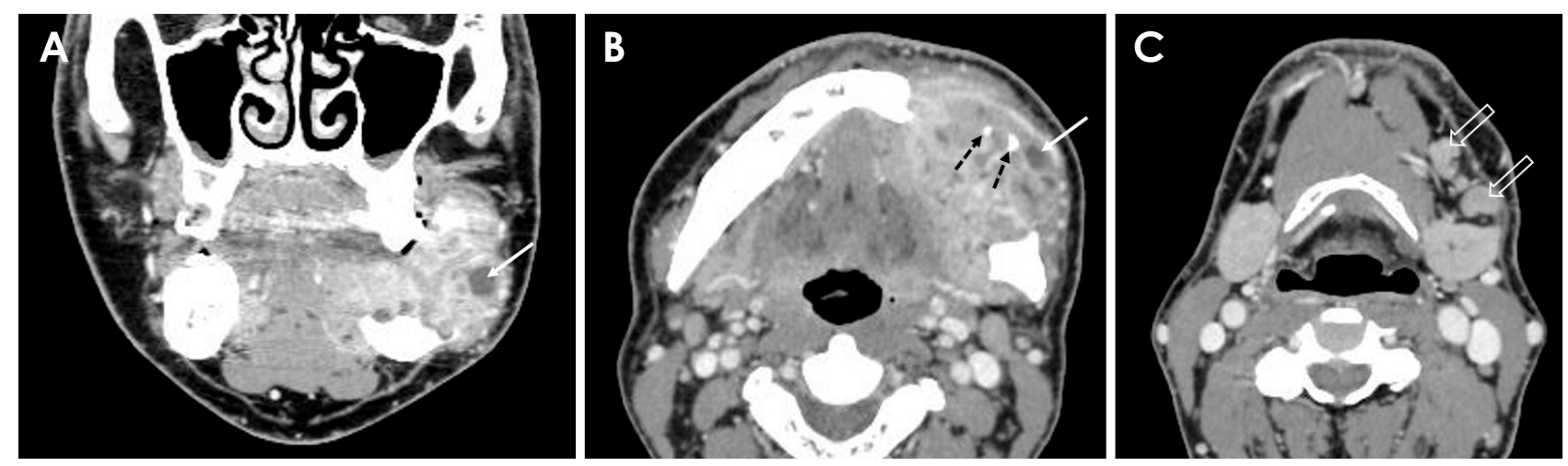

Fig. 4. Enhanced coronal (A) and axial (B and C) computed tomographic images show a large tumorous mass pushing out towards adjacent soft tissue bucco-lingually. Inside the tumor, the necrotic foci (arrows) and a few remaining bone particles (dotted arrows) are observed. C. There are several enlarged submandibular lymph nodes (open arrows).

definition of ameloblastic carcinoma since the term "ameloblastic carcinoma" was introduced by Elazy in 1982. ${ }^{12}$ In 1984, Slootweg and Müller proposed a definition and nomenclature used to distinguish ameloblastic carcinoma from malignant ameloblastoma. ${ }^{4}$ Ameloblastic carcinoma exhibits microscopic features of malignancy, regardless of the presence of metastasis, whereas malignant ameloblastoma is a microscopically benign tumor, but it metastasizes. $^{13,14}$

Ameloblastic carcinoma is extremely rare, accounting for fewer than $1 \%$ of all malignant neoplasms in the head- and-neck region. ${ }^{15}$ Nevertheless, it is the most common malignancy of odontogenic tumors. ${ }^{16}$ It may arise either de novo or from a preexisting odontogenic lesion. ${ }^{4,717}$ In this case, since the patient had no prior history of surgical procedures or radiation therapy in the region where the lesion occurred, it was assumed that the lesion arose de novo. However, it was not possible to completely rule out the possibility of secondary ameloblastic carcinoma by malignant transformation of a preexisting ameloblastoma given the long duration of the lesion and the patient's clinical history of tooth extraction. Ameloblastic carcinoma may occur 


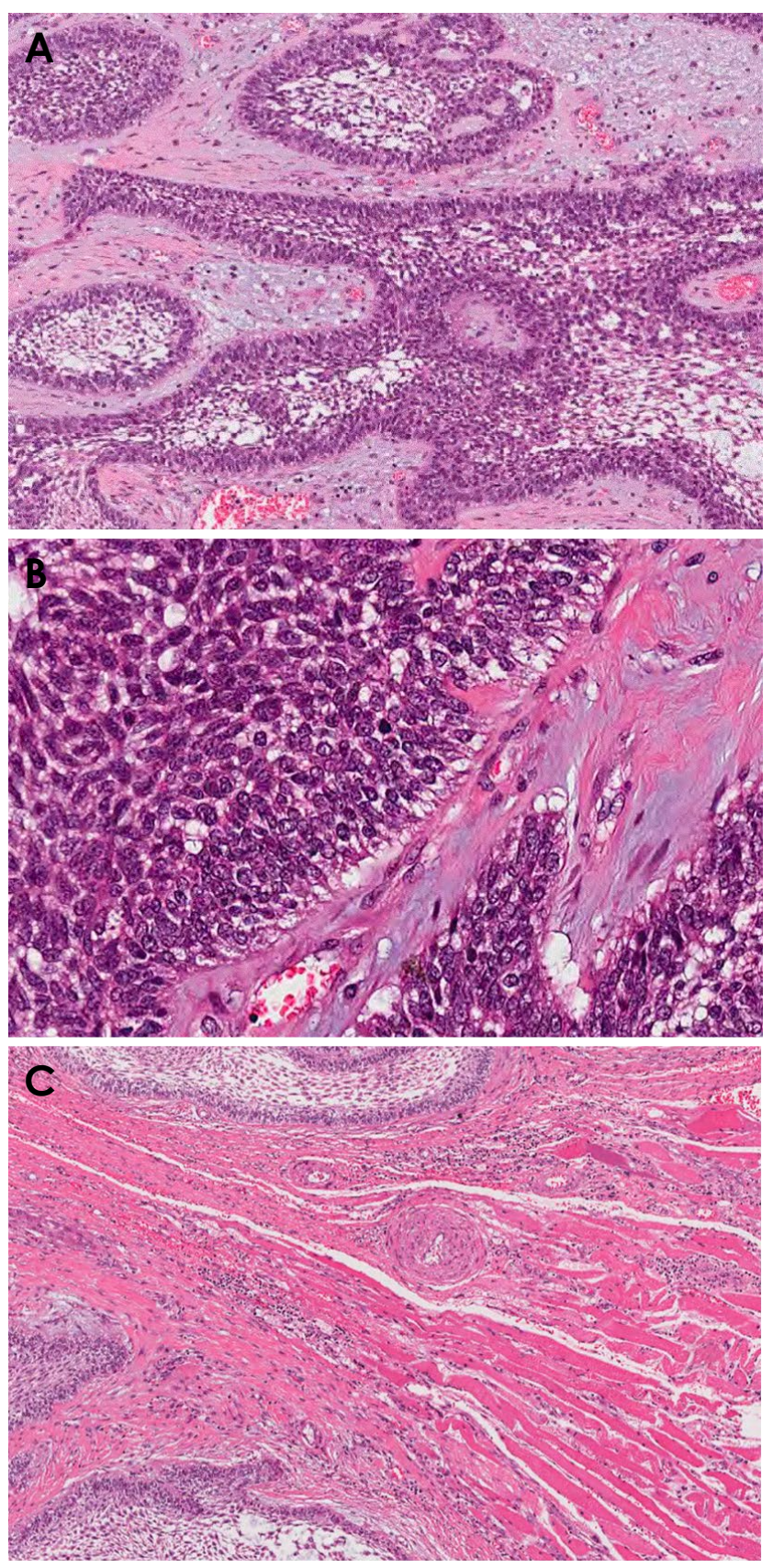

Fig. 5. A. Histopathologic examination shows tumor nests composed of a core of stellate reticulum-like cells and peripheral columnar cells $(H \& E$ stain, $\times 200)$. B. At high magnification, malignant features such as hypercellularity, cellular pleomorphism, and abnormal mitosis are observed (H\&E stain, $\times 400)$. C. Tumor nests invade muscular tissue with pushing margins $(H \& E$ stain, $\times 100)$.

in any age group with mean age of 44 years. ${ }^{18}$ Most studies have shown a slightly higher male predilection,,$^{9,8,18,19}$ although some studies have reported no apparent sex predilection. ${ }^{7}$ The posterior region of the mandible is the most frequent site of ameloblastic carcinoma. ${ }^{19}$ With regard to age, sex, and location, the case described herein is consis- tent with most other studies. ${ }^{9,18,19}$

Ameloblastic carcinoma presents aggressive clinical behavior. Akrish et al. ${ }^{20}$ described the characteristics of ameloblastic carcinoma as rapid growth, cortical perforation, pain, and paresthesia, all of which are uncommon features of ameloblastoma. In the current study, the patient presented with pain and showed severe cortical destruction. $\mathrm{He}$ did not, however, complain of any symptoms of sensory disturbances.

Ameloblastic carcinoma also presents various radiographic manifestations, with findings that may be similar to cysts, benign tumors, or other malignant tumors. ${ }^{6,91-25}$ In some cases, the radiographic appearance of ameloblastic carcinoma is very similar to that of ameloblastoma. Radiographically, both lesions can show either unilocular or multilocular radiolucency with tooth-root resorption and tooth displacement. ${ }^{14}$ Ameloblastic carcinoma may have either an ill-defined or a well-defined border, ${ }^{7,919,26,27}$ which makes it difficult to differentiate ameloblastic carcinoma from ameloblastoma. It is known that ameloblastic carcinoma can reveal focal radiopacities, which are rarely seen in ameloblastoma. Ameloblastic carcinoma may also have areas of necrosis with dystrophic calcification. ${ }^{8.9}$ In the present case, a necrotic spot was seen in the lesion, but there were no focal radiopacities. Several radiopaque spots were observed on cone-beam CT slices; however, these were interpreted as cortical particles that remained from severe expansion and resorption. In the present case, some areas showed multilocular radiolucency, as observable in benign lesions like ameloblastoma, but a provisional diagnosis of malignancy could be made based on the frank bone destruction with an undulating exophytic soft-tissue mass. Ameloblastic carcinoma can show marginal sclerosis without periosteal newbone formation, as in the case described herein. Although there are some cases where it could be difficult to distinguish between ameloblastic carcinoma and ameloblastoma, a careful clinical and radiographic examination can help in the differential diagnosis. With more aggressive biological behavior than ameloblastoma, ameloblastic carcinoma can trigger symptoms including pain, rapid growth, paresthesia, trismus, and dysphonia, ${ }^{7}$ whereas few of these symptoms occur in ameloblastoma. In addition, despite the benign radiographic features of well-defined radiolucency with cortical expansion, the presence of definite cortical resorption is a valuable clue in the differential diagnosis. Matsuzaki et $\mathrm{al}^{24}$ stated that CT is useful for distinguishing ameloblastic carcinoma from ameloblastoma because it can clearly show bone resorption; the authors of the present study found that it was also true for cone-beam CT, which demonstrated 
the pattern of bone resorption in detail. Ameloblastic carcinoma can also metastasize to the regional lymph nodes or the lungs. In this case, there were several enlarged cervical lymph nodes, but there proved to be no metastasis.

Surgical resection is the treatment of choice for ameloblastic carcinoma. It can recur locally 6 months to 11 years after definitive treatment, and distant metastasis may appear as early as 4 months or as late as 12 years postoperatively. ${ }^{28}$ Long-term surveillance is therefore needed.

In conclusion, ameloblastic carcinoma is a very rare malignant odontogenic neoplasm. It shows divergent clinical and radiographic manifestations, ranging from benign to malignant. Hence, it is often challenging to delineate ameloblastic carcinoma from ameloblastoma. Ameloblastic carcinoma can present with rapid growth, pain, paresthesia, trismus, exophytic ulcerated mass, severe cortical resorption, and focal calcification. If any of these features are seen, a prompt histopathologic investigation is needed. Early diagnosis and close periodical screening for recurrence and metastasis are necessary for a better prognosis.

\section{Conflicts of Interest: None}

\section{References}

1. Wright JM, Vered M. Update from the 4th Edition of the World Health Organization Classification of Head and Neck Tumours: odontogenic and maxillofacial bone tumors. Head Neck Pathol 2017; 11: 68-77.

2. Uzawa N, Suzuki M, Miura C, Tomomatsu N, Izumo T, Harada K. Primary ameloblastic carcinoma of the maxilla: a case report and literature review. Oncol Lett 2015; 9: 459-67.

3. Lolachi CM, Madan SK, Jacobs JR. Ameloblastic carcinoma of the maxilla. J Laryngol Otol 1995; 109: 1019-22.

4. Slootweg PJ, Müller H. Malignant ameloblastoma or ameloblastic carcinoma. Oral Surg Oral Med Oral Pathol 1984; 57 : 168-76.

5. Kramer IR, Pindborg JJ, Shear M. The WHO histological typing of odontogenic tumours. A commentary on the second edition. Cancer 1992; 70: 2988-94.

6. Prabhu VD, Vidya M, Lugman M, Kumarswamy KL, Roshith K. Ameloblastic carcinoma - a case report. J Indian Acad Oral Med Radiol 2003; 15: 58-61.

7. Corio RL, Goldblatt LI, Edwards PA, Hartman KS. Ameloblastic carcinoma: a clinicopathologic study and assessment of eight cases. Oral Surg Oral Med Oral Pathol 1987; 64: 570-6.

8. Benlyazid A, Lacroix-Triki M, Aziza R, Gomez-Brouchet A, Guichard M, Sarini J. Ameloblastic carcinoma of the maxilla: case report and review of the literature. Oral Surg Oral Med Oral Pathol Oral Radiol Endod 2007; 104: e17-24.

9. Yoon HJ, Hong SP, Lee JI, Lee SS, Hong SD. Ameloblastic carcinoma: an analysis of 6 cases with review of the literature. Oral Surg Oral Med Oral Pathol Oral Radiol Endod 2009; 108:
904-13.

10. Naik V, Kale AD. Ameloblastic carcinoma: a case report. Quintessence Int 2007; 38: 873-9.

11. Goldenberg D, Sciubba J, Koch W, Tufano RP. Malignant odontogenic tumors: a 22-year experience. Laryngoscope 2004; 114 : 1770-4.

12. Elzay RP. Primary intraosseous carcinoma of the jaws. Review and update of odontogenic carcinomas. Oral Surg Oral Med Oral Pathol 1982; 54: 299-303.

13. Pindborg JJ, Kramer IR, Torloni H. Histological typing of odontogenic tumors, jaw, cyst and allied lesions. World Health Organization; Geneva: 1971.

14. Kishore M, Panat SR, Aggarwal A, Upadhyay N, Agarwal N. Ameloblastic carcinoma: a case report. J Clin Diagn Res 2015; 9: ZD27-8.

15. Ponnam SR, Srivastava G, Sudhakar G. Ameloblastic carcinoma with diverse histological features: a case report. Int J Oral Maxillofac Pathol 2012; 3: 60-4.

16. Adebiyi KE, Odukoya O, Taiwo EO. Ectodermal odontogenic tumours: analysis of 197 Nigerian cases. Int J Oral Maxillofac Surg 2004; 33: 766-70.

17. Cizmecý O, Aslan A, Onel D, Demiryont M. Ameloblastic carcinoma ex ameloblastoma of the mandible: case report. Otolaryngol Head Neck Surg 2004; 130: 633-4.

18. Li J, Du H, Li P, Zhang J, Tian W, Tang W. Ameloblastic carcinoma: an analysis of 12 cases with a review of the literature. Oncol Lett 2014; 8: 914-20.

19. Soyele OO, Adebiyi KE, Adesina OM, Ladeji AM, Aborisade A, Olatunji A, et al. Ameloblastic carcinoma: a clinicopathologic analysis of cases seen in a Nigerian Teaching Hospital and review of literature. Pan Afr Med J 2018; 31: 208.

20. Akrish S, Buchner A, Shoshani Y, Vered M, Dayan D. Ameloblastic carcinoma: report of a new case, literature review, and comparison to ameloblastoma. J Oral Maxillofac Surg 2007; 65: 777-83.

21. Ram H, Mohammad S, Husain N, Gupta PN. Ameloblastic carcinoma. J Maxillofac Oral Surg 2010; 9: 415-9.

22. Lau SK, Tideman H, Wu RC. Ameloblastic carcinoma of the jaws. A report of two cases. Oral Surg Oral Med Oral Pathol Oral Radiol Endod 1998; 85: 78-81.

23. Abir B, Abouchadi A, Tourabi K, Lakouichmi M. Ameloblastic carcinoma of the mandible: a case report and review of the literature. Med Buccale Chir Buccale 2017; 23: 95-8.

24. Matsuzaki H, Katase N, Hara M, Asaumi J, Yanagi Y, Unetsubo $\mathrm{T}$, et al. Ameloblastic carcinoma: a case report with radiological features of computed tomography and magnetic resonance imaging and positron emission tomography. Oral Surg Oral Med Oral Pathol Oral Radiol Endod 2011; 112: e40-7.

25. Avon SL, McComb J, Clokie C. Ameloblastic carcinoma: case report and literature review. J Can Dent Assoc 2003; 69: 573-6.

26. McNaught MJ, Turella SJ, Fallah DM, Demsar WJ. Spindle cell variant of ameloblastic carcinoma: a case report and review of literature. Mil Med 2015; 180: e614-7.

27. Wu JY, Chi LH, Pemg BY, Lin YH. Ameloblastic carcinoma of the maxilla - case report. J Dent Sci 2007; 2: 164-70.

28. Ingram EA, Evans ML, Zitsch RP 3rd. Fine-needle aspiration cytology of ameloblastic carcinoma of the maxilla: a rare tumor. Diagn Cytopathol 1996; 14: 249-52. 